\title{
O desamparo dos adolescentes pobres na cidade de Maringá
}

\author{
The abandonment of the poor adolescents in the city of Maringa
}

http://dx.doi.org/10.5007/2178-4582.2016v50n2p375

\section{Angela Maria Pires Caniato \\ Monica Salci Capelasso}

Universidade Estadual de Maringá. Maringá/PR, Brasil

\begin{abstract}
Na contemporaneidade os vínculos interpessoais mostram-se mais frouxos, o consumismo se intensifica e a violência é incorporada de modo cada vez mais hostil, especialmente com relação aos adolescentes pobres. À luz da Psicopolítica (Freud e Theodor Adorno), foi feito um levantamento bibliográfico para obter maiorco mpreensão das ideologias que perpassam tais acontecimentos e das suas interferências na intensificação do preconceito, da apatia e do desamparo. Essas diferentes expressões da violência fragilizam a identidade subjetiva dos adolescentes de classes socioeconômicas desfavorecidas da cidade de Maringá - PR. Este artigo está vinculado ao Projeto Pesquisa Intervenção "PHENIX: A Ousadia do Renascimento do Indivíduo-Sujeito - Fase III", que sustenta essa compreensão e orienta uma proposta de cooperação junto a esses adolescentes, cujo objetivo é desenvolver um raciocínio crítico que os proteja para não caírem tão facilmente nas armadilhas truculentas - designação de malignidade e periculosidade - que a sociedade imputa sobre eles.

Palavras-chave: Desamparo; Indústria cultural; Adolescente pobre; Sociedade de consumo.
\end{abstract}

Nowadays, interpersonal bonds present themselves as looser, consumerism is intensifying and violence is incorporated in much more hostile way, especially toward adolescents from low income families. From the perspective of Psychopolitics (Freud and Theodor Adorno's Theory), a bibliographical research has been done, in order to obtain a greater understanding of the ideologies that pervades these events and their interrelationships, that result in the intensification of prejudice, apathy, and abandonment. These different expressions of violence undermine the subjective identity of adolescents from disadvantaged socio-economical classes from the city of Maringá - Paraná. This article is linked to the Participant Research on the Project "Phenix: The boldness of the Individual-Subject Revival - Stage 3", that supports this understanding in agreement with a cooperation proposal along with these adolescents, which aims to develop a critical thinking that protects them from falling so easily in truculent traps - designation of malignancy and hazard - that society imputes on them.

Keywords: Abandonment, Culture industry; Poor adolescent; Consumerism society.

\section{Os adolescentes de uma periferia de Maringá: alunos de uma escola pública}

"O desamparo, por sua vez, indica que a vida psíquica continua a ser vivida fora de si, no desespero da abertura para um outro que não responde". (Jacques André)*

A situação de vulnerabilidade do adolescente pobre pode ser evidenciada na cidade de Maringá a partir das intervenções do projeto "PHENIX - A Ousa- 
dia do Renascimento do Indivíduo-Sujeito- fase III", cujo objetivo é propiciar reflexões críticas por esses adolescentes. Nas nossas intervenções junto a eles, procuramos estar cooperando para a elaboração/libertação das situações psicossociais violentas a que estão expostos e que, quando internalizadas, produzem importantes estragos na constituição de suas identidades.Essas atividades são mediatizadas pelos discentes de Psicologia da Universidade Estadual de Maringá que integram o Projeto PHENIX (CANIATO, 2012).

Para efetivar nosso objetivo, buscamos desenvolver junto aos adolescentes um pensamento reflexivo, pautado numa crítica imanente, a fim de que esses jovens, que vivem em condições sociais adversas, possam se tornar agentes transformadores da realidade social. São propostas de Adorno (1995), que estão em sua obra Educação e Emancipação.

De acordo com essa proposta, a Pesquisa Participante - método utilizado nas intervenções - pela qual, de acordo com Thiollent (1981) e Brandão (1984), um dos objetivos é colocar em questionamento os princípios ideológicos que sustentam a produção do conhecimento. O princípio da neutralidade, por exemplo, cai por terra ao identificarmos que "nenhum conhecimento é neutro e nenhuma pesquisa serve teoricamente a todos dentro de mundos sociais concretamente desiguais" (BRANDÃO, 1984, p.11). Então, é exigido o engajamento sócio-político do pesquisador e da população participante. $\mathrm{O}$ desenvolvimento desse método ocorre por meio da relação entre o pesquisador (acadêmicos da UEM) e o grupo de pesquisa (adolescentes pauperizados), promovendo uma permanente e contínua relação de trocas reflexivas sobre a realidade vivida pelos indivíduos-alvo desse processo. Atingir uma relação de troca é um dos fundamentos exigidos por esse método de pesquisa, o que significa a manutenção de trocas afetivo/reflexivas em que fique explicitado o vínculo de compromisso entre os dois grupos. Dessa forma, inverte-se o autor do objeto de pesquisa: o problema a ser estudado deve surgir das indagações feitas pela própria população na relação de confiabilidade com o pesquisador. São as questões-demandas que são propostas pelos adolescentes. Na análise que a população vai fazendo de sua realidade, os pesquisadores vão dando feedbacks que auxiliem os adolescentes a organizarem suas ideias durante todo o processo de investigação.Sabidamente, esse tipo de vínculo só ocorre quando há uma constância de trocas afetivo-intelectuais entre os integrantes dos dois grupos de pesquisadores: acadêmicos de Psicologia e adolescentes pobres.

Caminhando sob esse procedimento e dirigidos pelas questões-demandas trazidas pelos adolescentes, vamos refletindo sobre suas preocupações, procurando fazer uma análise das contradições da sociedade que atravessam a vida dos indivíduos e distinguindo entre o que é e o que deveria ser. Buscamos uma compreensão dos indivíduos que vivem sob a lógica das forças dominan- 
tes da macroestrutura socialpara entender as articulações com a vida diária de cada um desses adolescentes e também da nossa enquanto acadêmicos.

Neste sentido, esperamos que no decorrer da nossa intervenção junto a esses adolescentes pauperizados, consigamos cooperar no desenvolvimento de um pensamento reflexivo que lhes permita estarem menos vulneráveis diante do poder de cooptação de preconceitos e de injustiças sociais. Entendemos também ser importante que eles consigam buscar o acolhimento junto aos seus pares, para que, num vínculo de solidariedade/amparo, possam desfazer a padronização a que estão expostos. A busca da autonomia e do respeito à alteridade do outro são posturas que procuramos manter.

As intervenções que servirão de ponto de referência para nossas afirmativas nesse trabalho foram realizadas em 2013, em uma escola da periferia da cidade que está localizada perto do Bairro Santa Felicidade, cujos moradores são pobres, portanto, mais suscetíveis à violência social e, por conseguinte, presas fáceis do desamparo. Isso se dá porque eles são em sua maioria de baixa renda, característica suficiente para serem discriminados como um perigo para a sociedade. Arpini (2003) analisa essa vinculação entre a pobreza, a exclusão e o desamparo:

\begin{abstract}
Conforme apontam Ariès (1981), Costa (1983) e Fraga (1996), as desigualdades sempre estiveram presentes nos diferentes momentos; a pobreza como consequência dessa desigualdade sempre representou um grande problema para as sociedades, pelas quais era vista como um aspecto perigoso. Tal perigo diz respeito, por um lado, ao mal-estar e à violência que poderiam decorrer da pobreza, e, por outro, ao risco de contaminação que a pobreza representava, devido ao seu estilo de vida e seus hábitos, os quais a moral e a higiene, principalmente a partir do século 18 , vão condenar duramente. Data, inclusive, dessa época, a reclusão das pessoas pobres, doentes e loucas que, por andarem soltas pelas ruas, representavam um perigo para a sociedade. Esse fato marca toda nossa história e hoje representa um dos grandes problemas da sociedade contemporânea, sobretudo porque a desigualdade social não foi aqui minimizada pelos avanços e o progresso alcançado nesses anos, haja vista que o Brasil é um dos países com a pior distribuição de renda no mundo. (ARPINI, 2003, p.37, grifos nossos)
\end{abstract}

De acordo com Coimbra (2005, p. 01), a partir do século XX o Brasil tem imputado ao jovem pobre, rótulos de "perigoso, criminoso e, portanto, não humano".

Estes discursos discriminatórios são ideologias que atingem as populações da chamada classe baixa.Ele é culpabilizado por esta sociedade que the tira direitos e o desumaniza. Entretanto, a lógica do capitalismo neoliberal já 
está atravessada pela desigualdade/exclusão social desde sua base econômica e por si só justifica as medidas coercitivas que são executadas pelo aparato de repressão do Estado - a polícia. Tais ações de violência estão amparadas judicialmente sob o manto de ser a chamada violência legítima (MICHAUD, 1988).

Essa injustiça é corroborada quando os adolescentes que integram a nossa pesquisa-intervenção enfaticamente identificam a polícia como sendo o "deserto", que na lenda da Phenix representa as condições inóspitas a que a ave estaria submetida em seu habitat. De fato, tais adolescentes estão submetidos à devastação destrutiva do deserto (ação discriminatória e truculenta da polícia). Eles comentaram que alguns deles foram "enquadrados" pela polícia quando conversavam num bar localizado em frente à escola. Também já foram molestados pela Patrulha Escolar ${ }^{1}$ dentro da mesma, acusados de serem agentes de bocas-de-fumo, isto é, portadores/usuários de drogas ilícitas. Ainda mais, eles afirmaram sentir-se envergonhados por serem alvo desses abusos da autoridade policial.

Nesse momento foi-lhes sugerido que fossem espertos para não caírem na armadilha da polícia, ou seja, que tivessem uma conduta cuidadosa para evitar maiores represálias. Assim, os adolescentes foram instigados a pensar (função consciente do ego) acerca da verticalização arbitrária da relação quando estão submetidos à violência da polícia. Nessas condições tornam-se mais vulneráveisà internalização da malignidade a eles preconceituosamente imputada, em especial, por estarem em um período de fragilidade na estruturação das suas identidades. Sob o impacto da internalização dessa violência, os adolescentes assimilam como próprias, as diferentes maledicências que lhes são impingidas e são jogados no desamparo psicossocial ao identificarem-se com seus agressores e, consequentemente, terem exacerbado seu sadomasoquismo. Freud (1917/1996) afirma:

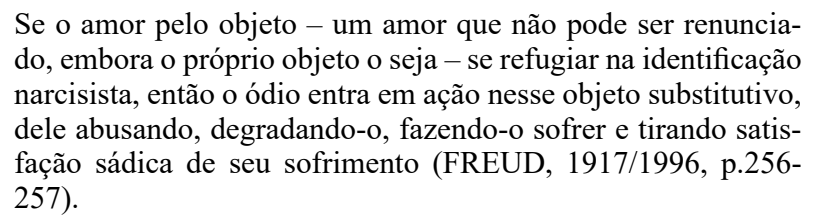

Laplanche e Pontalis (2001, p. 231), fazem referência a Anna Freud para elucidar que o mecanismo de identificação com o agressor possui duas fases no que diz respeito ao conteúdo agressivo. Em um primeiro momento "o

1 Patrulha Escolar se caracteriza por ser uma repartição da polícia do estado do Paraná que patrulha crianças e adolescentes nos bairros pobres e escolas da periferia da cidade de Maringá. 
agressor é introjetado, enquanto a pessoa atacada, criticada, é projetada para o exterior". Após a introjeção do agressor e a projeção no objeto, a "agressão se voltará para o interior e a relação no seu conjunto é interiorizada".

Nesse sentido, a constituição do adolescente pobre, submetido à violência de Estado, tem como modelo identificatório o ataque social/policial, a hostilidade e a ofensa social, que fica evidenciado com o direcionamento dessa violência contra o próprio ego e os seus objetos. Sob esse laço hostil, o adolescente pobre tende a sentir satisfação em degradar a si próprio, visto que a identificação com o agressor lhe faz "sentir forte e importante". Há de se considerar a ambivalência de julgar que merece ser mal tratado para se sentir pertencente a uma sociedade, embora viva sob ofensas e privações. Em outras palavras, esse traço sadomasoquista acompanha o processo de socialização desses jovens, nessa entrega à autoridade e ao descarrego de sua "agressividade nos grupos de contraidentificação (sadismo)" (CARONE, 2012, p.19).

Carone (2012) faz uma releitura da pesquisa de Theodor Adorno sobre "A Personalidade Autoritária" e demonstra que esse processo subjetivo de identificação com o agressor é "administrado" pela sociedade autoritária que, ao conseguir essa forma de cumplicidade dos indivíduos, se exime de ser a autora de atos violentos contra esses grupos excluídos: trata-se da "estrutura psicológica do sujeito fascista". É nessa trama que os adolescentes pobres, marginalizados como violentos e perigosos, acabam por cumprir esses papéis que lhes são atribuídos socialmente e justificar a violência social que recai sobre eles.

Outra questão evidenciada pelos adolescentes foi a personificação dos objetos/mercadorias que são tidos como referência para a formação de suas identidades. Em uma das intervenções, por exemplo, alguns alunos afirmam que é bom usar "roupas de marca"; mas que, segundo a opinião de outros, as roupas não mudam a forma de cada um ser, o que muda é apenas a forma de eles serem vistos pelos outros. Mantendo a apropriação de suas "ideias" pela propaganda, outro aluno expôs que "não liga se não tiver roupa de marca, mas se tiver, ajuda".

Nesse momento, na tentativa de fazer os adolescentes refletirem sobre o que foi relatado por eles, foi questionado o que mudaria ser visto pelos outros de forma diferente, não só pela aparência de uma etiqueta, mas pelo significado que isso teria em sua autoestima e na relação com aqueles que lhes observam. Em outras palavras, foi problematizado se de fato uma marca, carregada de ideologias, lhes serviriam como expressão de suas singularidades e de vínculos de alteridade.

Essas concepções de encontrarem na mercadoria/marca uma identidade, corroboram a necessidade de estes jovens serem aceitos pela sociedade 
por meio do poder de compra que eles não possuem, forçados que são pela indústria cultural que só atribui importância social aos indivíduos que têm possibilidade de consumir. Por isso alguns adolescentes pobres acabam por buscar, por meios legais ou ilegais, a condição de consumidor pelo desejo de serem reconhecidos e respeitados enquanto indivíduos, conforme dita a lógica do livre-mercado. Nesse cenário social os investimentos libidinais, que antes eram direcionados ao vínculo com o outro, agora tendem a ser destinados à mercadoria - incapaz de proporcionar amparo. Tal realidade pode ser considerada ainda mais evidente em se tratando dos adolescentes pobres da periferia de Maringá - cidade reconhecidamente excludente -uma vez que estão submetidos a uma hierarquização muito bem definida de divisão de classes sociais pela especulação imobiliária. Desde a criação da cidade,vem sendo delimitados claramente os bairros residenciais nobres - onde moram os ricos; o centro e a periferia da cidade - reservada aos pobres (RODRIGUES, 2004). Diante disso, a exclusão social se faz clara mediante a vigência de uma política econômica segregacionista que, porém, imputa a esses indivíduos a responsabilidade pelo seu fracasso, enquanto pertencentes a uma "sociedade livre, igualitária e fraterna".

É nesse contexto que os adolescentes de periferia estão imbricados: submetidos à violência simbólica da mercadoria e quase sem chances de defesa, em decorrência da fragilidade inerente a sua vida nessa coletividade de excluídos, o que traz sérios prejuízos à sua constituição psíquica em formação. Entendemos, então, que tais influências ideológicas perversas perpassam seu ego em construção, tornando esses adolescentes vulneráveis, presas fáceis dos preconceitos que lhes são socialmente imputados. A submissão desses adolescentes, enquanto classe menos favorecida e atravessada pela indústria cultural, se constitui em uma desestruturante internalização da violência a que ficam expostos sob o sistema econômico capitalista, que nega direitos a eles e verticaliza privilégios.

Os adolescentes pobres fazem parte de um grupo de indivíduos que, como muitos outros, sofrem fortes preconceitos excludentes, sendo vítimas de uma sociedade de consumo que estimula competições e categoriza os indivíduos hierarquicamente. Diante disso, tornou-se importante entender o desamparo (palavra alemã Hilflosigkeit), na tentativa de depreender a dinâmica psicossocial que permeia as relações intersubjetivas desses adolescentes, visto que eles sofrem o desamparo social em sua maior dimensão: o alijamento e a exclusão de classe social.

Entretanto, fica difícil para cada indivíduo despregar-se da política ideológica massificadora da sociedade atual que explora de forma mistificadora a exigência de felicidade do ser humano. Funda-se na difusão de falsas ideias 
de felicidade, mascarando o sofrimento decorrente do esvaziamento das relações entre os indivíduos e promovendo a absorção/subalternização de cada indivíduo aos ditames da mercadoria via indústria cultural. Essa "felicidade" forjada pela ideologia atravessa o inconsciente desejante daqueles que, assim, se desvirtuam e abandonam a procura do amor-no-outro e caem nessas armadilhas de sofrimentos inevitáveis, que alimentam/sustentam suas condições de "bodes expiatórios". É inevitável que nessa desesperança abandonem seus possíveis amigos/parceiros cuja presença os fortaleceria.

Fica evidente que a exposição desses adolescentes à violência social é mais contundente porque sobrevivem em uma sociedade marcada pela distinção depreciativa entre os seres humanos: os que podem ter acesso à mercadoria e os que são alijados de todo e qualquer bem social. Essa exclusão social, não assumida pelos atores sociais dominantes, traz em seu bojo a culpabilização desses adolescentes, intimida-os no pertencimento ao coletivo e os responsabiliza pelos próprios fracassos. A ânsia e expectativa a que são induzidos até a idolatria de ter um "tênis de marca", quando frustrada, pode induzi-los à plena identificação com o que lhes é imputado socialmente: serem os "perigosos" em potencial. Acerca das impossibilidades socioeconômicas desses adolescentes, Arpini (2003) explica:

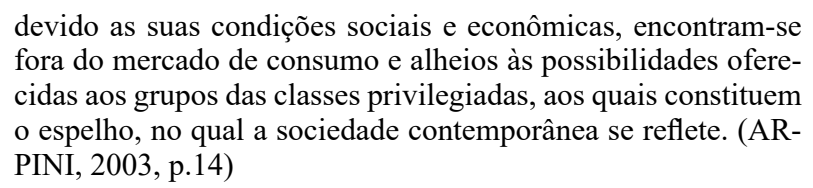

Desse modo, os processos identificatórios desses adolescentes encontram mais suporte e aderência naquilo que a sociedade identifica neles como maléfico, fazendo-os assimilar os estereótipos que lhes são atribuídos socialmente como originários de seu mundo interno. Crescem sob o individualismo e a primazia da mercadoria, que valoriza o indivíduo pelo que ele possui; correm atrás da mentira de poderem ser felizes pela posse da mercadoria que não conseguem obter e acabam caindo nas malhas da repressão policial que os espreita e vigia.

A ampliação desses vínculos de auto ataque se estende às relações entre os pares quando as acusações mútuas e as delações de um contra o outro os afastam entre si e impedem as relações de companheirismo. Durante a história de vida desses adolescentes, são perdidas/contaminadas as relações interpessoais que teriam a incumbência de ser fonte de amparo para uma estruturação psíquica saudável. Não havendo uma relação de troca satisfatoriamente amorosa, são geradas trocas acusatórias violentas e, um possível pedido de ajuda 
a um potencial parceiro é visto como incompetência individual, merecedora de ser desprezada e sofrer deboche. O que prevalece não é a mediação do parceiro-diferente para a construção da autonomia identitária, e, sim, a truculenta identificação com o agressor.

Assim, entendemos que o desenvolvimento da reflexão crítica desses adolescentes com os quais convivemos poderá evitar que tais acusações arbitrárias a eles dirigidas resultem em graves consequências contra os mesmos, não os deixando nas malhas de um sofrimento sadomasoquista.

Não obstante, mesmo não sendo possível, ao menos em um futuro próximo, alterar a dimensão macro dessa sociedade que propicia diferentes formas de violência - a exclusão social, o descaso, o abandono e o desamparo - a micropolítica apresentada nas intervenções do Projeto "PHENIX: a Ousadia do Renascimento do Indivíduo-Sujeito - Fase III" pode vir a se constituir como uma forma de resistência ao mostrar a esses adolescentes a possibilidade de desmistificarem as ideologias que capturam suas individualidades e cooperar com eles no desenvolvimento de suas capacidades de refletir criticamente, na autonomia subjetiva e nos vínculos grupais de solidariedade e amparo.

Mas até onde esses adolescentes conseguem sair da imobilidade em que a violência simbólica da indústria cultural os colocou e emergir como cidadãos amados e respeitados - agentes da cultura?

\section{Maringá: da exclusão dos rolezinhos nos shoppings à dos adolescentes na periferia da cidade}

\footnotetext{
Para os pobres restam regiões de moradia nas quais «não há áreas de lazer ou escolas para todos os níveis de educação, [e] a violência coloca em perigo a vida de todos, mas principalmente a dos jovens". (ARAÚJO, 2005, p.81)

Muitos dos adolescentes da escola pública da periferia de Maringá em que desenvolvemos o Projeto PHENIX são moradores do bairro Santa Felicidade e adjacências.
}

Vejamos um movimento recente de adolescentes que esteve atuante há pouco tempo e foi muito comentado na mídia em geral: o dos "rolezinhos". Nele, um contingente considerável de adolescentes da periferia se encontrava nos shoppings para se conhecer, conversar e "curtir" essa fase da vida, que geralmente é marcada por muito agito. Beguoci (2014) aponta que esses jovens são apenas adolescentes "dopados" de hormônios que querem "aprontar por aí" e, pertencentes a qualquer classe social. Refere ainda o autor: 
Os rolezinhos são grandes festas em espaços privados. Quem conhece a periferia de São Paulo sabe que existem pouquíssimos espaços em que seja possível fazer uma festa, reunir os amigos ou almoçar fora de casa num domingo. (BEGUOCI, 2014, p.13)

Desta maneira, os shoppings se tornaram alguns dos poucos espaços "seguros" para o encontro desses jovens. A proibição de estar ali não tardou e, sob diferentes injunções violentas de policiais, foram expulsos. Não é ali o lugar deles. Na cidade de Maringá (PR), localizada na Região Noroeste do Paraná, os adolescentes da periferia também foram a um shopping no centro da cidade e, como já era esperado, foram revistados e coagidos pela polícia. Fica evidente que esses adolescentes, dadas as circunstâncias sociais dentro da cidade, apenas elegeram os shoppings para passarem momentos de lazer junto a seus grupos identitários. Porém, esse fenômeno, conforme aponta Beguoci (2014), vira alvo fácil dos radicalismos políticos: ora tais jovens são exaltados por estarem atuando a favor da livre circulação de todos, ora são recriminados em defesa da propriedade privada. Sem ao menos se darem conta desses discursos de uma minoria considerada "politizada que os endeusam ou criminalizam", essesadolescentes sofrem a truculência da polícia em nome de uma "segurança preventiva", porque "em áreas mais violentas, todo mundo é uma ameaça - inclusive o vizinho ou cliente que escuta som alto" (BEGUOCI, 2014, p.14). O resto da população tornada condescendente, assiste silenciosa a essa violência policial que segrega e discrimina aqueles que são considerados perigosos porque são pobres. Esse fenômeno está evidenciado na Figura 1.

Figura 1: Fotografia mostrando a revista policial feita nos adolescentes que estavam em um "rolezinho" na cidade de Maringá.-Fonte: ALMENARA ANDRE, 2014.

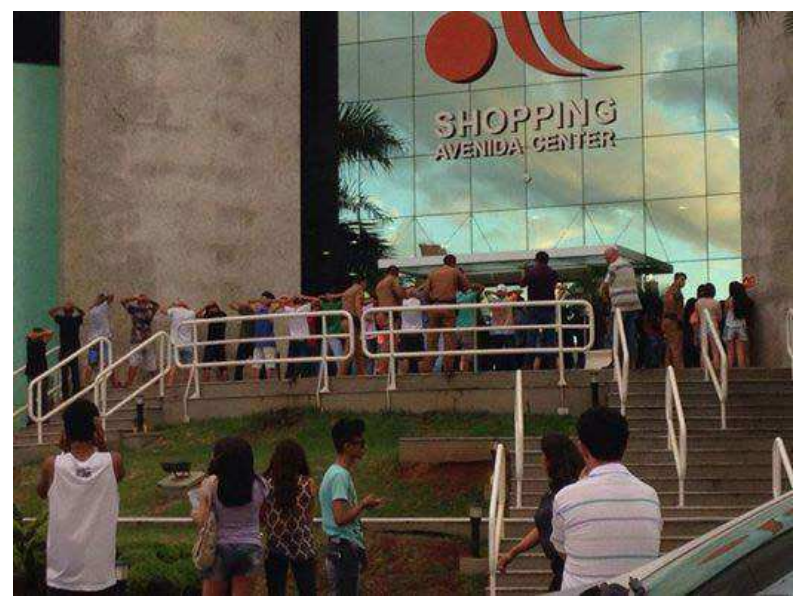


Os shoppings são espaços de aglomeração privilegiados de um outro tipo de pessoas que têm um estilo de vida alinhado ao consumo e que estão modeladas para a compra dos objetos propagandeados como "personificadores". Apesar de serem indivíduos capturadospela indústria cultural, essa elite se regozija em ostentar suas aquisições em desfiles exibicionistas. Em particular, os moradores de Maringá, até pelas propagandas que exaltam a cidade, se julgam privilegiados por morarem em uma das melhores cidades do país em que não caberia a presença destes adolescentes forasteiros. Para evidenciar essas distinções, Rodrigues (2004) discorre sobre o planejamento dessa cidade que é motivo de orgulho para seus moradores de classe média/alta:

O projeto que norteou o desenvolvimento da cidade foi cumprido integralmente, inclusive, nos aspectos que definiram uma ocupação residencial diferenciada socialmente. Ao segmentar as áreas a serem comercializadas, segundo as especificidades socioeconômicas dos adquirentes, o agente imobiliário fomentou, ao longo de mais de meio século, uma ocupação residencial claramente segregada. Contudo, há um conjunto de moradores cujas rendas sequer alcançaram a possibilidade de ter acesso à moradia em Maringá, e que foram expulsos para o entorno da cidade polo, em especial, para Sarandi e Paiçandu. (RODRIGUES, 2004, p.6, grifos nossos)

Maringá foi planejada de modo a proteger-se de inúmeros problemas que assolam as cidades que têm favelas e ocupações irregulares, sendo os de menor poder aquisitivo expulsos para as pequenas cidades de seu entorno. Segundo Rodrigues (2004), a cidade é tida como referência nacional entre as cidades de porte médio, em especial, por serem seus administradores capazes de conter as ditas anomalias sociais do perímetro urbano.

Maringá foi sendo construída para atender às exigências da especulação imobiliária, em comum acordo com o poder público. Deste modo, conforme Rodrigues (2004), o perímetro urbano foi segmentado tendo como parâmetro uma hierarquia social: a área central e a Zona 2 foram ocupadas pela classe média alta "pelo valor dos lotes, mais elevado neste bairro, que o das outras áreas residenciais (RODRIGUES, 2004, p.56)”, pertencentes às áreas periféricas (Zonas 3 e 4), destinadas à população pobre.

Maringá foi fundada em 1947 e emancipada em 1951. Luz (2001) aponta que a região foi colonizada por uma empresa cujo nome era Companhia Norte Melhoramentos do Paraná (CMNP), que manteve esse ideário elitista na delimitação das diferentes "Zonas" residenciais ${ }^{2}$ e reservou um espaço na zona 
central de sua gleba de quinhentos e quinze mil alqueires, para ser um local privilegiado, um estabelecimento que seria 'um dos mais importantes centros urbanos do Norte do Paraná'.

Para que tais objetivos fossem alcançados, essa mesma empresa se incumbiu de propagandear para todo o país, como nos lembra Gonçalves (2001), os esplendores da nova região, identificando-a sob nomes pitorescos tais como "Nova Canaã", "Eldorado", "Terra Onde se Anda sobre Dinheiro", "Terra da Promissão" e demais designações de interesse publicitário.

Desse modo, muitas famílias de diversas regiões do país que estavam em busca de vida melhor, foram atraídas para Maringá na esperança de conquistar uma vida mais digna e próspera, passando a habitar os espaços "elegantemente pensados e rigorosamente traçados" para ser uma cidade "bela e pujante", na qual não caberiam pobres.

Além do controle territorial sob o qual a cidade foi construída, desde o início houve uma segregação planejada dos ricos e pobres em espaços considerados diferenciados e sob o prisma de valores elitistas, tendo como parâmetro serem os ricos "homens de bem", indivíduos mais honrados e dignos. Maringá, desde o projeto de sua criação, esteve envolvida nessa perspectiva elitista: a cidade foi apelidada de Cidade-Jardim pela Companhia de Melhoramentos Norte do Paraná, tendo como modelo as cidades inglesas de Howard e, em especial, a de Owen, "entendida como comunidade perfeita e autossuficiente [...] com a tônica, entretanto, colocada mais na privacy do que nas relações sociais: uma tentativa de subtrair à vida familiar a promiscuidade e adesordem da metrópole" (BENÉVOLO, 1976, p. 356, apud RODRIGUES, 2004, p.29).

Para manter esse ideário de "cidade modelo", nas décadas de 70 e 80, período em que muitas cidades brasileiras passaram pelo processo de "favelização", a administração de Maringá não permitiu que o mesmo acontecesse com ela. Os moradores das favelas existentes em torno do Cemitério Municipal, situada próxima ao centro - Zona 02 -, "foram transferidos para núcleos populares construídos com recursos públicos, como é o caso do bairro denominado Santa Felicidade" (RODRIGUES, 2004, p.75).

Com a justificativa de manter o planejamento inicial e contribuir para uma habitação "mais digna para esses favelados", a administração da cidade preservou ao longo dos anos o "processo de segregação residencial das pessoas de baixas rendas para fora dos espaços destinados às elites" (RODRIGUES, 2004, p.76).Para concretizar esse processo, além do Bairro Santa Felicidade, criado para transferir os indivíduos pobres que moravam nas "áreas nobres" da cidade, foi criado o Conjunto Roberto Requião e construídas casas em Iguatemi e Floriano, e as "cidades de Sarandi (Jardim Independência) e 
Mandaguaçu (Vila Guadiana) que também se constituíram em espaços que acolheram os desfavelados de Maringá" (RODRIGUES, 2004, p. 75).

Nesse contexto, conforme denuncia Rodrigues (2004), a cidade de Maringá e seu entorno inserem-se:

no processo mais abrangente de polarização riqueza-pobreza que caracteriza a urbanização no Brasil, reproduzindo o tradicional modelo de ocupação do espaço urbano centro-periferia e, neste sentido, apresentando uma ocupação socialmente hierarquizada, distinguindo-se do modo fractal que vem caracterizando, atualmente, a urbanização nas grandes metrópoles, com o espraiamento da riqueza por todo o território. (RODRIGUES, 2004, p.229)

Como afirmativa desse processo de exclusão social, até as áreas comerciais foram segregadas, visto que foram criados nas periferias, estabelecimentos comerciais e de serviços de diferentes especialidades, para que seus moradores não precisassem se deslocar para as áreas centrais, espaço destinado para a circulação da classe média e alta da cidade.

Rodrigues (2004, p. 83) afirma que, devido a essa segregação bem delimitada, os espaços públicos da cidade se tornaram comprometidos, "pois os habitantes das áreas centrais admitem que os espaços públicos (praças e ruas) sejam ocupados apenas enquanto áreas de circulação e não áreas de permanência". A Praça da Catedral Nossa Senhora da Glória - no centro da cidade -, por exemplo, passou a ser usada para encontros da população pobre, mas sob intensa vigilância policial, até os dias de hoje.

Esse processo de segregação espacial revela traços perfeitamente condizentes com a desigualdade social de Maringá. Como já afirmamos, essa forma de segregação não se restringe a essa cidade, pois, segundo Araújo (2005, p.83), a desigualdade advém "da história e estrutura das cidades, contemporaneamente partes da organização capitalista que é, em si, desigual. Com seu avanço e desenvolvimento temos ainda mais desigualdade". Porém, Maringá vem encontrando estratégias para mascarar essas contradições, Araújo (2005) afirma:

Quando essa situação de desigualdade, percebida na maioria das cidades, não ocorre, trata-se de uma exceção, ou de uma forma singular da cidade, de conviver com ela, isso, talvez, sirva apenas para confirmar a regra de que as cidades são desiguais e separam, ou melhor, segregam para áreas mais distantes, parte de sua população com menor poder aquisitivo, pouca instrução e cuja mão-de-obra não é especializada, ou seja, os pobres. (ARAÚJO, 2005, p.82) 
Maringá continua sendo uma cidade administrada pela elite local que vem instituindo, de forma normalizadora, políticas higienistas com respaldo da imprensa local e permitindo o uso da violência policial para expulsar os indesejáveis da cidade. À proporção que a cidade cresce em direção à periferia, faltam espaços para os condomínios fechados e, os "indesejáveis" do bairro Santa Felicidade voltam a ser coagidos para sair de lá, para onde não se sabe. Não por coincidência, Maringá é uma cidade na qual não existem favelas.

Esse bairro, segundo Araújo (2005, p, 161), "foi pensado como uma solução para se terminar com os pontos de favela ainda existentes na cidade". No entanto, a criação desse bairro não trouxe benefícios para essas famílias que foram ali alojadas, uma vez que a Prefeitura Municipal dificultou o acesso aos bens sociais, para que não fosse possível que essa população chegasse ao centro ou que constituísse outras favelas dentro da cidade. Isto é, o Santa Felicidade foi criado na tentativa de isolar os indivíduos pobres do resto da população. As famílias transferidas para lá, "tinham suas vidas observadas e controladas de perto pelo poder público municipal" (Araújo, 2005, p. 157), e eram taxadas de vadias, bandidas, sem ambições e responsabilizadas pela sua condição de miséria. Não podiam trazer familiares para visitá-los sem a autorização de uma assistente social da Fundação de Desenvolvimento Social de Maringá, órgão da Prefeitura Municipal.

A segregação espacial presente na história familiar da maioria dos adolescentes que frequentam a escola pública em que desenvolvemos o Projeto PHENIX, também vem deixando marcas simbólicas na constituição de suas identidades. O descaso com essa população, de acordo com a história oficial de Maringá, fez com que eles representassem "infatigavelmente a violação, a libertinagem e o desvio moral" (CAMPOS, 1999, p. 326). Desse modo, esses adolescentes estão mais suscetíveisà truculência policial, pois além de serem filhos da exclusão social da cidade de Maringá, sua faixa etária é ideologicamente estigmatizada com tendências antissociais. O psicanalista David Léo Levisky (1998), por exemplo, corrobora com tal preconceito quando atribui ao adolescente uma possível atitude social com tendências antissociais ou associais de diversas intensidades, que podem caminhar para contradições excessivas em sua conduta.

Ainda podemos constatar que a população de alto poder aquisitivo da cidade de Maringá, se autoidentificando como "trabalhadores que cultuam valores morais e os bons costumes", não medem esforços para manter tal aparência. Então, é simplório para eles desenvolver um mecanismo projetivo que atribui aos adolescentes pobres a malignidade que tal elite não teria. Em outras palavras, a elite local, que desde sua fundação aprova políticas higienizadoras para manter o status de "Cidade Modelo", endossa a maciça violência policial 
contra a população pobre, projetando sua agressividade/malignidade nos adolescentes dessa classe social.

Essa malignidade que foi atribuída às famílias dos adolescentes do Bairro Santa Felicidade no passado, permanece e é intensificada na atualidade de maneira bastante evidente por meio da Patrulha Escolar, que realiza intensa vigilância policial nas escolas da periferia da cidade e nos bairros onde mora a pobreza da cidade.

\title{
As implicações da indústria cultural na identidade dos adolescentes pobres
}

A influência cultural na construção da identidade do adolescente - associada a todas as características que são próprias dessa etapa da vida - é capaz de produzir formas de pensamento e direcionar atitudes, além de modelar subjetividades, principalmente porque esses indivíduos se encontram em processo de elaboração/desenvolvimento psicoemocional. Porém tal influência não é evidente, mas sim camuflada por uma ideologia presente na atual sociedade capitalista neoliberal, que incita o adolescente ao consumo irrestrito. Severiano, discorrendo sobre a importância social de consumir, explica:

\begin{abstract}
Assim, celulares, carros, computadores, cartões de crédito, corpos "sarados" etc. são convertidos em uma espécie de passe para a inclusão social e um certificado de estilo e personalidade, sem o necessário estabelecimento de vínculos de alteridade. (SEVERIANO, 2010, p.121)
\end{abstract}

Com isso a mercadoria passa a ser um referencial para a formação da subjetividade do indivíduo, substituindo a identificação e a relação de amparo com o outro diferente, pela posse do objeto-consumo. Acerca da imposição do Capital de formar subjetividades para o consumo irrestrito, Severiano afirma:

\footnotetext{
"o capitalismo de então passa a elaborar estratégias nas quais o próprio desejo passa a ser socialmente 'educado' por agências 'extrafamiliares' (Marcuse, 1975), a exemplo da publicidade, que a partir da década de 1920 e 1930 transforma-se em uma instância cultural e simbólica de extrema significação na ação normativa social, passando a ter uma função de socialização que anteriormente pertencia apenas aos grupos primários." (SEVERIANO, 2010, p.126, grifos nossos)
}

A apologia ao consumo - que verticaliza os indivíduos quanto a sua importância social e expressa a subalternização do humano pela mercadoria (fetichismo da mercadoria-Marx) - transforma o homem em objeto (coisificação 
do homem) e atribui características humanas ao inanimado (personificação da mercadoria): a mídia é o importante aliado na difusão/incrementação da indústria cultural (ADORNO; HORKHEIMER, 1985).

Dessa maneira, os indivíduos perdem sua capacidade de questionar/entender os apelos/normas que lhes rodeiam, de emancipar-se e poder transformar seu meio social (ser agentes da cultura), pois o que acontece, segundo Severiano (2010, p.129), "é uma crescente e intensa substituição dos ideais culturais, que poderiam ser forjados na relação com o outro, por ideais particularistas do consumo, que se forjam na relação com o 〈objeto-signo〉".

A manipulação que se processa é feita sutilmente, de modo a induzir ao consumo indiscriminado, ou seja, a consciência destruída passa a não exercer seu atributo seletivo e discriminatório. Sob os efeitos disruptivos dessa violência simbólica, os indivíduos seguem de forma passiva os ditames dos poderes dominantes, por que ficam equalizadas e normatizadas suas subjetividades, visto que todos os indivíduos introjetam necessidades perversamente inventadas como se fossem próprias da condição humana.

A função da indústria cultural, nesse contexto, é equalizar todos os indivíduos por meio de ideologias que assimiladas pelo inconsciente, direcionam seus desejos e dominam suas consciências e, por conseguinte, atitudes. Assim, o Ego é enfraquecido sem a possibilidade de uma reflexão crítica e sob essa fragilização fica à mercê dos ideais de consumo, tendentes à busca dos falsos prazeres exigidos pelo mercado. Para a manutenção desse processo, ocorre uma "dessublimação" conduzente à fragilização dos processos reflexivos. Nesse sentido, Severiano (2010) afirma:

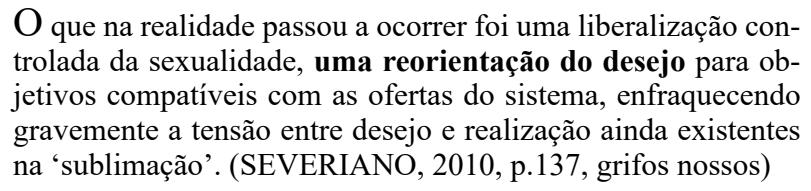

Assim, pela falta de discernimento daquilo que realmente trará benefícios e bem-estar aos indivíduos, o comprar se lhes torna indiscriminado. Os adolescentes, em seus variados grupos, engolfados por essa lógica hedonista, acreditam que possuem um "estilo próprio" de consumir e que de fato estariam atendendo suas necessidades individuais. Nas palavras de Severiano (2010):

agora, a racionalização ideológica se sofistica e argumenta que, diante da "diversidade" de produtos, diferentes segmentos podem 'eleger' os bens de acordo com seu "estilo". A dita "de- 
mocracia" passa, então, a se basear na capacidade de "eleição individualizada", na "livre escolha" dos bens de consumo. (SEVERIANO, 2010, p.127, grifos nossos)

Nesse cenário, por conseguinte, a individuação do homem é falsificada, tornando-se uma "'pseudo-individuação', (ADORNO; HORKHEIMER, 1985), que não visaria à diferenciação entre indivíduo e sociedade, mas sim à mimese, à homogeneização das consciências" (SEVERIANO, 2010, p.133). Em outras palavras, a "pseudo-individuação" é uma suposta diferenciação que o indivíduo acredita fazer ao escolher o que compra, visto que todo o espectro de estilos para o consumo já foi padronizado a priori pelo mercado e por sua representação simbólica - a indústria cultural- fazendo com que a adesão aos produtos se dê pelas identificações idealizadas. Como a subjetividade dos adolescentes depende do processo de socialização que se constrói nos tempos atuais - em meio às ideias disseminadas pelos veículos de publicidade (mídia) - os processos identificatórios são suscetíveis à introjeção desse modo de ser indivíduo-consumista. Fica evidente que a construção das individualidades dos adolescentes sob a lógica do mercado e, em particular dos adolescentes pobres, se dá sob o signo da identificação com o agressor e do sentimento de culpabilidade (Freud, 1930/1996), que corrói seus psiquismos desde dentro e os expõe às mentiras consumistas, pois, de fato, nem conseguem comprar o que passam a querer.

Esclarecendo um pouco mais, os processos identificatórios construtores das identidades dos adolescentes na contemporaneidade (sob os ditames sedutores da indústria cultural na sociedade da mercadoria), são expressão ideológica - uma violência simbólica - que, quando internalizada, tem forte apelo à normatização das subjetividades, funcionando como estratégia de controle social. Isso porque as diferenciações entre os indivíduos são descaracterizadas e as alteridades negadas, deixando os indivíduos à mercê de uma simbiose narcísica (instinto de morte) em que prevalece uma "lógica" reprodutora da intolerância ao diferente. Todo esse processo se sustenta no individualismo que protege o sistema capitalista, mas é perverso para os indivíduos porque cada um necessita de uma vinculação sólida de amor com o outro, de uma vinculação que viabilize a troca libidinal mútua e promova o fortalecimento do Ego e, consequentemente, de sua identidade individual: a mercadoria não tem amor para dar aos indivíduos. Destarte, são cristalizadas suas formas de "pensamentos" que, minados/reprimidos por essa ideologia - que reproduz os ditames sociais -, torna os indivíduos vítimas (em especial os pobres) que ainda carregam a exigência de encobrir as injustiças sociais, negadas socialmente, que atravessam a construção de suas individualidades. 
Assim, a ideologia da indústria cultural é um fenômeno de controle social, que quando introjetada, se insere no funcionamento simbólico consciente e inconsciente, direcionando desejos impregnados de prazer/morbidade. Os grupos sociais marginalizados sofrem intensamente os efeitos disruptivos dessas introjeções, até ao ponto de se culpabilizarem/mutilarem como se delinquentes fossem. Assim, as diferenciações de classes sociais, já fundadas nas relações de trabalho (extração da mais valia), são re-qualificadas pela atribuição de malignidade a esses grupos de indivíduos - certos preconceitos sociais - que funcionam como armadilha perigosa instituída socialmente para ofuscar a diferenciação entre o eu e o não-eu e não permitir a distinção/diferenciação das condições objetivas do pertencimento de classe social.

Nessas circunstâncias, a propagação da lógica da mercadoria como valor "supremo" instaura a apologia ao consumismo e, o investimento libidinal da relação com o outro humano é deslocada para a relação com a mercadoria. Essa inversão ideológica esvazia a amorosidade individual/relacional, constituindo-se no que Green (1998) denomina de 'narcisismo de morte' que integra a inexistência de trocas libidinosas entre indivíduos: a mercadoria não tem libido para nos envolver. É uma falsa satisfação que, entretanto, desencadeia a compulsão na procura de novos "objetos de desejo", novas aquisições de mercadoria (consumismo). Mais ainda, o simbólico da ideologia com a sua maledicência mentirosa (violência), penetra na intimidade psíquica e passa a acionar os desejos disruptivos (instinto de morte) do indivíduo. O indivíduo afasta-se cada vez mais do outro nessa busca incessante de uma fácil/falsa satisfação no consumo da mercadoria e abandona mais e mais a si e ao outro indivíduo humano capaz de garantir-lhe o amparo necessário. Nessa lógica, o amparo amoroso é substituído pelo desamparo hostil e pela ilusão de satisfação com a mercadoria: essa é a principal forma do DESAMPARO na contemporaneidade.

Sob a forma social de ser indivíduo-consumista como "valor humano", aos pobres que não têm acesso ao extenso campo das provocações mercadológicas por terem baixa renda, só resta internalizar/sofrer a imputação de categorias preconceituosas: serem "vagabundos, preguiçosos, viciados, ladrões, etc".

\section{Os impactos do truculento desamparo social na construção da identidade dos adolescentes pobres:}

Sob todo esse impacto disruptivo do desamparo, o adolescente pobre vai sobrevivendo sob essas limitações socioculturais, tendo de enfrentar a competição desenfreada sem ter dinheiro para elevar-se na hierarquia consumista. 
Nesta sociedade de classes, na qual o pobre é malquisto, o adolescente pobre tende a introjetar com facilidade o preconceito, que, segundo Caniato (2008, p.22), "[é uma atribuição social de malignidade a determinados indivíduos e grupos, correspondente a uma categorização de classe social ${ }^{3}$ que, muitas vezes, veicula uma atitude política e étnica aversiva". Desse modo, conforme Caniato (2008) é por meio dos processos de identificações que os adolescentes pobres internalizam essa malignidade que lhes é imputada.

Coimbra (2005) afirma que a discriminação social é inerente à lógica do capitalismo liberal, no qual o pobre tem apenas a liberdade/obrigatoriedade de seguir os princípios atribuídos a sua classe social que, na sua essência, é vender sua força de trabalho para o mercado. Tal exploração da força de trabalho (mais valia) é camuflada pela falsa ideia (ideologia) vigente, desde a Revolução Francesa, que instituiu como princípios burgueses que todos têm os mesmos direitos. Escondendo a diferenciação de classe social, recai sobre o indivíduo solitário toda e qualquer diferenciação de status social. Diante dos "insucessos" já forjados socialmente, as suas fraquezas são realçadas como incapacitantes e, portanto, causadoras desses fracassos: a culpabilização recai sobre o indivíduo-trabalhador-pobre que já carrega em suas costas os fardos depositados por seus algozes/capitalistas.

Coimbra (2005) afirma que para existir riqueza, acúmulo de capital, é necessária a exploração da miséria. Logo, a competitividade e a desigualdade são intrínsecas a uma sociedade que atua como se fosse igualitária e prega a enganosa "liberdade, igualdade e fraternidade". Como herança de uma sociedade racista e eugenista, o pobre possui uma "moral duvidosa", segundo a qual aquele pobre que é trabalhador e respeitador das leis sociais tem que viver sob valores morais ainda mais restritivos, porque vive em um meio exposto a "vícios" e "doenças". É nesse sentido que aqueles que não trabalham, são "um 'perigo social' que deve ser erradicado; daí a necessidade de medidas coercitivas, principalmente para essa parcela da população, pois são criminosos em potencial" (COIMBRA, 2005, p.05).

Há uma predisposição a julgar crianças e adolescentes pobres como uma ameaça social o que, entretanto, não se mostra explicitamente. A justificativa para tal injustiça advém de teorias que "estabelecem/fortalecem a relação entre vadiagem/ociosidade/indolência e pobreza, bem como entre a pobreza e periculosidade/violência/criminalidade" (COIMBRA, 2005).

Entretanto, as crianças e os adolescentes pobres são adestrados a silenciar. Como uma estratégia de controle, eles são treinados para a conformação à

3 Isso significa dizer que o preconceito é usado socialmente, também, como um dos qualificadores culturais de classe social. A diferenciação social de classe se constitui na relação básica do sistema econômico de produção capitalista (relação proprietários-trabalhadores) para a extração da mais valia- essência da diferenciação de classe social. 
penúria. De forma dissimulada, são convencidos a acreditar que não adianta tentar ter ambições, pois são incapazes de emergir a outros níveis de vida que não seja o da miséria. Contraditoriamente, para esconder a violência dessa opressão, há de ser continuamente mantida a ilusão de que, se se esforçarem, conseguirão tudo que desejam e poderão "subir na vida", pois em "nada são diferentes daqueles ricos que gozam das benesses sociais: entretanto, só no nível de fantasias inconscientes tornadas 'verdades', é possível essa ascensão".

Esta violência que recai sobre o outro - no caso, o adolescente pobre - é entendida como uma projeção daquele indivíduo que reprime a si mesmo com o intuito de suportar o sofrimento sentido. Afirma Adorno (1986) apud Caniato (2008):

\begin{abstract}
Aquele que é duro contra si mesmo adquire o direito de sê-lo contra os demais e se vinga da dor que não teve a liberdade de demonstrar, que precisou reprimir. Este mecanismo deve ser conscientizado, da mesma forma como deve ser fomentada uma educação que não mais premie a dor e a capacidade de suportá-la. [...] não devemos reprimir o medo. Quando o medo não for reprimido, quando nos permitirmos ter tanto medo real quanto essa realidade merecer, então possivelmente muito do efeito destrutivo do medo inconsciente e reprimido desaparecerá (ADORNO, 1986b, apud CANIATO, 2008, p. 22)
\end{abstract}

O impacto inconsciente-consciente desse preconceito social, conforme Caniato (2008), conduz à ineficiência das funções egoicas dos indivíduos que, assim, não conseguem discriminar o opressor social real do imaginário subjetivo. Com essa adesão, mesmo que inconscientemente, os indivíduos/adolescentess e tornam, então, cúmplices das ideologias perversas que passam a direcionar seus desejos, pensamentos e ações.

Diante dessa realidade, a tendência é que se estabeleçam vínculos frouxos entre os pares, visto que a violência social intimida e impede relações permeadas por laços afetivos fortalecedores das identidades. Caniato (2008) aponta que os atos de vandalismo, cometidos individualmente ou em grupos, acabam sendo uma forma de externar o ressentimento de uma violência sofrida, ocasionando alívio temporário; porém tais atitudes corroboram o caráter de perigoso que é atribuído a essa classe baixa e resultam em punição/represália social armada/legitimada pelo Estado (poder policial). O sofrimento psicossocial se institui no cotidiano como forma de ser e viver dos indivíduos da classe subalternizada.

Porém, como postula Freud (1930/1996, v. 21) em Mal Estar na Cultura, existe um sofrimento real vinculado à decadência gradual do corpo, à impotência humana diante das adversidades da natureza e dos traumas vividos nos conflitos psicossociais. Quando o sofrimento nas relações psicossociais 
se faz presente de modo contínuo, direciona o modo como a vida tende a ser administrada, ou seja, a todo o tempo o indivíduo se depara com situações de violência em que sua vulnerabilidade estrutural e seu desamparo constitucional são mobilizados. As injunções sociais violentadoras internalizadas são assimiladas pelos indivíduos como originárias em seu mundo interno - sentimento de culpabilidade -(Freud, 1930/1996), e passam a corroer a sua vida cotidiana. Assim, a consciência é direcionada rumo a uma regressão egoica, deixando o indivíduo a mercê de uma identidade constituída pela má troca das fantasias inconscientes e disruptivas, que ficam sob a manipulação da mídia. Sobre isso, Crochick (1996) afirma:

junto à ameaça existe a percepção do sofrimento que obriga a consciência a cada vez mais se encolher frente à realidade e a procurar objetivos externos sobre os quais possa projetar a sua própria impotência. Os preconceituosos vêem no objeto aquilo que eles têm de negar a si mesmo: a fragilidade, o desamparo (CROCHIK, 1996, p.57)

A busca incessante da felicidade também faz parte da constituição da subjetividade a partir da pulsão de vida que atravessa toda a estrutura psíquica à procurado real objeto de satisfação e seu acolhimento; mas na contemporaneidade essa procura é cada vez mais insana e submetida a grandes empecilhos e distorções do que seja ser feliz: os indivíduos se deterioram sob esse truculento desamparo.

Para Freud (1914/2004. p.106), “[...]precisamos começar a amar para não adoecer, e iremos adoecer se, em consequência de impedimentos, não pudermos amar".

\section{Referências}

ADORNO, T. W. Educação e emancipação. Trad. Wolddgang Leo Maar. São Paulo: Paz e Terra, 1995.

ADORNO, T, W; HORKHEIMER, M. Dialética do esclarecimento. Trad. Guido Antonio de Almeida. Rio de Janeiro: Zahar, 1985.

ARAUJO, M. C. O bairro Santa Felicidade por ele mesmo. Espaço urbano e formas de representações sociais em Maringá, Paraná. 2005. 299 f. Tese (Doutorado em Sociologia)-Universidade Estadual Paulista Júlio de Mesquita Filho, Araraquara, 2005.

ARPINI, M. A. Adolescência, situação de risco e violência. In: Violência e exclusão: adolescência em grupos populares. Bauru: EDUSC, 2003.

BEGUOCI, L. Rolezinho e a desumanização dos pobres. Disponível em: < $\underline{\text { http://www.oene. }}$ 
com.br/rolezinho-e-desumanizacao-dos-pobres/> Acesso em: 20 mar. 2014.

BRANDÃO, C. R. Pesquisa Participante. São Paulo: Brasiliense, 1984.

CAMPOS, P. F. S. Moralizando o pobre: vadios, baderneiros e loucos na "cidade tecnicamente planejada para ser bela e sem problemas” In: DIAS, R. B.; GONÇALVES, J. H. R. (Orgs.). Maringá e o norte do Paraná: estudos da história regional. Maringá: EDUEM, 2001. p. 315-331.

CANIATO, A. M. P. Subjetividade e violência: desafios contemporâneos para a psicanálise. Maringá: Eduem, 2009.

CANIATO, A. M. P. O Projeto PHENIX a partir de 2008. In: Pesquisa Participante: um diálogo com adolescentes de periferia. Maringá: Eduem, 2012.

CANIATO, A. M. P. A violência do preconceito: a desagregação dos vínculos coletivos e das subjetividades. Disponível em: <http://pepsic.bvsalud.org/scielo.php?pi-

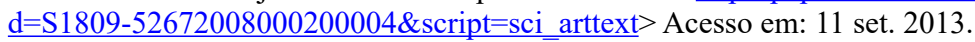

CARONE, Y. A personalidade autoritária: estudos frankfurtianos sobre o fascismo. Revista Sociologia em Rede, Goiânia, v. 2, n. 2, 2012.

COIMBRA, C. M. B.; NASCIMENTO, M. L. Ser jovem, ser pobre é ser perigoso? Disponível em: $<$ http://www.slab.uff.br/images/Aqruivos/textos sti/Maria $\% 20 \mathrm{~L} \% \mathrm{C} 3 \%$ ADvia $\% 20$ do\%20Nascimento/texto23.pdf $>$. Acesso em: 25 mar. 2014.

CROCHIK, J. L. Preconceito, indivíduo e sociedade. Disponível em: <http://www.ip.usp.br/ portal/index.php?option $=$ com content $\& v i e w=$ article $\&$ id $=2264 \% 3$ Alaep $=$-publicacoes\&catid358\&Itemid=211> . Acesso em: 15 mar. 2013.

FREUD, S. Ego e o Id e outros trabalhos, 1923. In: Edição Standard Brasileira das Obras Psicológicas Completas de Sigmund Freud. Rio de Janeiro: Imago, 1996, vol. 19, p. 23-83.

FREUD, S. O Mal-estar na civilização. 1930. In: Edição Standard Brasileira das Obras Psicológicas Completas de Sigmund Freud. Rio de Janeiro: Imago, 1996, vol. 21.

FREUD, S. Luto e melancolia, 1917/1915. In: Edição Standard Brasileira das Obras Psicológicas Completas de Sigmund Freud. Rio de Janeiro: Imago; 1996. vol. 14, p. 256-257.

FREUD, S. À guisa de introdução ao Narcisismo (1914). In: Escritos sobre a psicologia do inconsciente (Vol. 1). Rio de Janeiro: Imago. 2004. p. 95-132

GREEN, A. Narcisismo de vida e narcisismo de morte. São Paulo: Escuta, 1998.

GONÇALVES, J. R. H. Quando a imagem publicitária virá evidência factual: versões e reversões do norte (novo) do Paraná. - 1930/1940. In: DIAS, R. B.; GONÇALVES, J. H. R. (Orgs.). Maringá e o norte do Paraná: estudos da história regional. Maringá: EDUEM, 2001.

JACQUES, A. Estudos em Teoria Psicanalítica. Ágora, Rio de Janeiro, v. 4, n. 2, 2001.

LAPLANCHE, J.; PONTALIS, J. B. Vocabulário de Psicanálise. São Paulo: Martins Fontes, 2001 . 
LEVISKY, D. L. Adolescência: reflexões psicanalíticas. 2. ed. rev. e atual. São Paulo: Casa do Psicólogo, 1998.

LUZ, F. Maringá: fase de implantação. In: DIAS, R. B.; GONÇALVES, J. H. R. (Orgs.). Maringá e o norte do Paraná: estudos da história regional. Maringá: EDUEM, 2001. p.123-140

MICHAUD, Y. La Violence. Paris: PressesUniversitaires, 1988.

SANTOS, M. A; PRATTA, E. M. M. Adolescência e uso de drogas à luz da psicanálise: sofrimento e êxtase na passagem. Tempo psicanalítico, Rio de Janeiro, v. 44I, p.167-182, 2012.

SEVERIANO, M. F. V. "Lógica do mercado" e "lógica do desejo": reflexões críticas sobre a sociedade de consumo contemporânea a partir da escola de Frankfurt. In J. C. SOARES, J. C. (Org.), Escola de Frankfurt: inquietudes da razão e da emoção. Rio de Janeiro: EdUERJ, 2010. p.121-141

THIOLLENT, M. Crítica metodológica, investigação social e enquete operária. 2. ed. São Paulo: Polis, 1981.

RODRIGUES, A. L. A Pobreza mora ao lado: segregação socioespacial na região metropolitana de Maringá. Tese (Doutorado em Ciências Sociais), PUC - São Paulo, 2004.

Submissão em: 09/02/2015

Revisão em: 10/01/2016

Aceite em: 07/04/2016

Angela Maria Pires Caniato é Mestra e Doutora em Psicologia pela Universidade de São Paulo. Trabalha com a Psicanálise sob a abordagem Psicopolítica de Theodor Adorno e vem publicando artigos em Revistas e Livros fundamentados na TEORIA CRÍTICA. Coordena projeto de Pesquisa Intervenção sob esse enfoque teórico-metodológico. Atualmente é Professora do Curso de Mestrado e Doutorado em Psicologia - linha de Pesquisa Epistemologia e Práticas Sociais - da Universidade Estadual de Maringá-PR (UEM). Atua como pesquisadora nos seguintes temas: Psicanálise; Indústria Cultural; Violência, Preconceitos Sociais e Subjetividade.É representante do Núcleo de Maringá da Associação Brasileira de Psicologia Social (ABRAPSO). Recebeu a medalha ALFEPSI 2015.(Asociación Latinoamericana para La Formación y Enseñanza de la Psicologia). Possui experiência na área de Psicologia Clínica Psicanalítica e realiza atendimentos psicoterapêuticos sob essa linha teórico- metodológica. Endereço para correspondência: Mestrado em Psicologia. Universidade

Estadual de Maringá. Maringá/PR, Brasil. E-mail: angelacaniato@gmail.com

Monica Salci Capelasso é Psicóloga. Mestranda em Psicologia na Universidade Estadual de Maringá - PR. E-mail: monicapelasso@gmail.com 